\title{
Community health workers can improve child growth of antenatally-depressed, South African mothers: a cluster randomized controlled trial
}

Mark Tomlinson ${ }^{1 *}$, Mary Jane Rotheram-Borus ${ }^{2}$, Jessica Harwood ${ }^{2}$, Ingrid M. le Roux ${ }^{3}$, Mary O'Connor ${ }^{2}$ and Carol Worthman ${ }^{4}$

\begin{abstract}
Background: Maternal antenatal depression has long-term consequences for children's health. We examined if home visits by community health workers (CHW) can improve growth outcomes for children of mothers who are antenatally depressed.

Methods: A cluster randomized controlled trial of all pregnant, neighbourhood women in Cape Town, South Africa. Almost all pregnant women ( $98 \%, N=1238)$ were recruited and assessed during pregnancy, two weeks post-birth (92\%) and 6 months post-birth (88\%). Pregnant women were randomized to either: 1) Standard Care (SC), which provided routine antenatal care; or 2) an intervention, The Philani Intervention Program (PIP), which included SC and home visits by CHW trained as generalists ( $\mathrm{M}=11$ visits). Child standardized weight, length, and weight by length over 6 months based on maternal antenatal depression and intervention condition.

Results: Depressed mood was similar across the PIP and SC conditions both antenatally ( $16.5 \%$ rate) and at 6 months (16.7\%). The infants of depressed pregnant women in the PIP group were similar in height (height-forage $Z$ scores) to the children of non-depressed mothers in both the PIP and the SC conditions, but significantly taller at 6 months of age than the infants of pregnant depressed mothers in the SC condition. The intervention did not moderate children's growth. Depressed SC mothers tended to have infants less than two standard deviations in height on the World Health Organization's norms at two weeks post-birth compared to infants of depressed PIP mothers and non-depressed mothers in both conditions.
\end{abstract}

Conclusions: A generalist, CHW-delivered home visiting program improved infant growth, even when mothers' depression was not reduced. Focusing on maternal caretaking of infants, even when mothers are depressed, is critical in future interventions.

Trial registration: ClinicalTrials.gov registration \# NCT00996528. October 15, 2009

Keywords: Maternal depression, infant growth, stunting, South Africa, community health workers

\section{Background}

In the most recent analyses of the Global Burden of Disease by the World Health Organization, mental and behavioural disorders are the largest contributors to the years lived with disability (YLD), accounting for $22.7 \%$ of all YLD [1]. Depression is the most common of the mental health challenges [2] with the highest YLD (3.7 \%), and is

\footnotetext{
* Correspondence: markt@sun.ac.za

'Department of Psychology, Stellenbosch University, Private Bag X1,

Matieland, South Africa

Full list of author information is available at the end of the article
}

about twice as common among women compared to men [3]. Yet, to date, mental illness has not achieved commensurate visibility or funding compared to other diseases, particularly in low and middle income countries (LMIC) [4]. Despite the high prevalence of mental disorders and the known association with poverty [5], data on the consequences of depression, particularly maternal depression, is limited for LMIC [6].

Maternal depression has repeatedly been demonstrated to negatively impact both mothers and their children $[7,8]$. Globally, children of depressed mothers show 
deficits in cognitive, physical, and social development, with the most significant deficits demonstrated among children in LMIC [9]. Children of depressed mothers consistently demonstrate mental health problems [10], yet the infant developmental outcome most affected by maternal depression remains unclear [11, 12].

This study focuses on infants of antenatally depressed mothers in a community sample of pregnant women in South Africa over the first six months of life. Though less well documented than postpartum depression, depression in pregnancy is significantly associated with adverse child outcomes [13-17], including poor child growth $[18,19]$. However, depression also co-varies with a range of related stressors. Perinatal depressed mood is also associated with poverty and life stress [20] which are in themselves strongly related to poor child growth. In South Africa, up to $47 \%$ of women have been diagnosed with major depression across the perinatal period [21-23]. Key aspects of infant development (e.g., growth) are compromised in the context of parental poverty and mental health problems [9, 24]. Concurrently, depressed mothers in LMIC are likely to experience overcrowding, food insecurity and poor sanitation [25]. Infant growth is more complex than being based solely on food security and caloric intake. Factors such as the health environment, availability of health care, and feeding and care practices of the mother influence infants' growth.

In the context of antenatal depression and poverty, retarded infant growth has consistently been linked to maternal depression in Asia, with multiple studies in Pakistan [26] and Vietnam [27]. In Asia, the studies have been conducted with both clinical and community samples, and cross-sectional and longitudinal data. However, there have been inconsistent results regarding the impact of maternal depression on growth in South Africa [28], Ethiopia [27] and Malawi [29].

Identifying sustainable and effective strategies to improve maternal and child outcomes in LMIC is a high priority [30]. Intervention trials with postnatally depressed mothers have hypothesized very different mechanisms by which children are influenced by maternal depression [31]. Depressed mothers may provide sub-optimal care which has detrimental effects on the health of her child [6]. Depression may compromise care-giving behaviours (e.g., ensuring adequate hygiene, optimal nutrition through breastfeeding, immunization, recognizing illness and seeking care), as well as responsive parenting that is needed for physical and mental development of a child. In Pakistan the children of antenatally depressed mothers showed growth retardation in the first year of life [25]. When the mothers received home visits by $\mathrm{CHW}$, maternal depression was reduced, but infants did not improve weight- or length-for-age over the first year of life [32].
Maternal and child health intervention strategies have tended to address only one health risk at a time. As a result many studies provide little insight on the confluence of challenges faced by mothers in LMIC. Our project evaluated a community-based, home visiting program utilising CHW who were trained to address multiple health challenges facing pregnant South African mothers and their newborn infants. The $\mathrm{CHW}$ were trained to conduct home visits that addressed nutrition, alcohol, and HIV among pregnant township women, but not maternal depression. The training approach aimed to teach principles of behaviour change [33], based on cognitivebehavioral principles (CBT). CHW supported the mother to problem solve her own situation, rather than to provide solutions for her daily stressors and health challenges. While the CHW did not focus specifically on depressed mood, many of the factors related to positive child outcomes were addressed by the CHW. We report the child growth outcomes over the first six months of life, based on intervention status and maternal depression.

\section{Methods}

The Institutional Review Boards of University of California Los Angeles (UCLA), Stellenbosch University, and Emory University approved the study, whose methods have previously been published [34]. Three independent teams conducted the assessment (Stellenbosch), intervention (Philani Maternal, Child Health, and Nutrition Project, hereafter referred to as Philani), and data analyses (UCLA).

\section{Study context}

Cape Town contains five major peri-urban settlements (townships) with formal and informal rudimentary housing. Unemployment in Cape Town townships is estimated at between 25 and $50 \%$ [35]. Most women live within $5 \mathrm{~km}$ of a prenatal clinic. In each area, there is formal housing and vast areas of informal houses (shacks).

\section{Participants}

In 2009, 26 township neighborhoods were matched on size (450-600 households), density, public utilities (water, electricity, toilets), distance of primary health care, and the number of alcohol bars. UCLA randomized matched pairs of neighborhoods to either the PIP or SC condition. The minimum number of pregnant women needed per neighbourhood to achieve $80 \%$ power to detect a standardized effect size of 0.40 set the sample size; the original size was 1238. Participant flow through each phase of the study can be seen in Fig. 1.

\section{Procedure}

A recruiter obtained consent to contact and repeatedly visit all households in all neighbourhoods from May 2009 


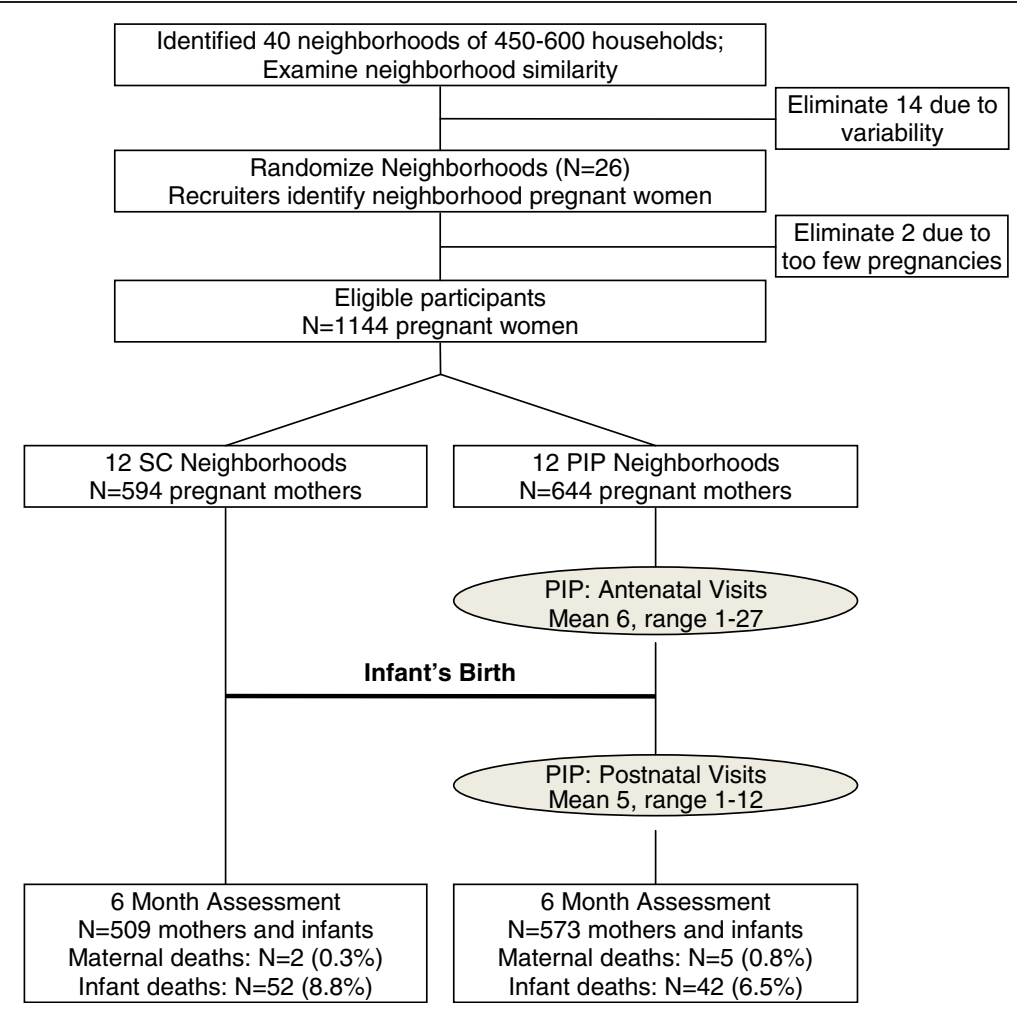

Fig. 1 Trial profile

to September 2010 in order to identify all pregnant women. Only $2 \%$ of pregnant women refused participation.

\section{Intervention conditions}

\section{Standard Care (SC) condition}

All mothers had relatively easy access to antenatal and postnatal care. Treatment for depression is theoretically possible, but it is highly unlikely that health care providers would identify or refer cases of depression, unless symptoms of active psychosis were detected during a clinic visit. Because the HIV rate in this population is about $26 \%$, standard clinic care includes HIV testing of virtually all women and extensive treatment for Mothers Living with HIV (MLHIV), including the following: dual therapy for Prevent Mother To Child Transmission (PMTCT), referral to antiretroviral therapy (ART) for women with CD4 counts below 200 or World Health Organization Stage 4 disease, the return of PCR test results for infants by 6 weeks of age, and co-trimoxazole for exposed infants starting at 6 weeks of age [36]. Nutritional supplements were also available from clinics during this study period.

\section{Philani Intervention Program (PIP)}

Philani is a non-governmental organization (NGO) that has been operating in Cape Town townships for more than 30 years. Local township women with good social skills and who were mothers themselves were recruited and trained as CHW to visit the homes of pregnant women and intervene to reduce alcohol misuse, increase adherence to perinatal HIV regimens, and boost child nutrition. CHW's were trained in: 1) cognitive-behavioural approaches to establishing healthy routines and to problem-solving around goal setting, choices, triggers, and shaping of desirable behaviours; 2) key information about general maternal and child health, techniques for framing each health issue that is a risk (nutrition, alcohol, and HIV), and strategies for applying the health information in families' daily lives; and 3) coping with their own life challenges. Trainers actively rehearsed and observed videotapes about how to solve challenging life situations, build engaging relationships, and keep responsibility for change with the mother. CHW were supervised weekly (face-toface supervision as well as via mobile phones), and randomly observed twice a month. Specific PIP content has been described in more detail elsewhere [34].

\section{Data collection}

A driver transported all participants to a central assessment site, allowing interviewers to be blinded to condition. All women provided written informed consent to participate in data collection. All data were collected using mobile phones [37]. Data collectors were taught methods of assessing infants' growth, strategies for 
building rapport and collecting honest answers, and how to interact in a non-judgmental manner. Before going into the field, all data collectors observed five client interviews and practiced interviewing skills. All $\mathrm{CHW}$ were certified by supervisors prior to becoming interviewers.

\section{Measures \\ Maternal mood}

Maternal mood was assessed at the baseline recruitment interview during pregnancy and at 6 months post-birth using the Edinburgh Postnatal Depression Scale (EPDS), a 10-item measure, with items rated on a scale of $0-3$ for severity [38]. The EPDS is a screening tool and is not used to make a confirmatory diagnosis of clinical depression; however, for the purposes of this study, we used a cut-off score of $>18$ to indicate the probable presence of depression [23]. Screening tools, by definition, will not have the sensitivity or specificity of a clinically validated tool such as the Standard Clinical Interview [39]. If the goal was to measure prevalence, we would have wanted to maximize sensitivity and accept some degree of falsepositives. In this study however, we wanted to maximize specificity to reduce false positives, so we used the highest recommended cut-point to increase the chances that a screen positive was a definite case, likely to represent cases of severe depression [40].

\section{Infant measures}

Anthropometric measures Weight and length was measured at two weeks post birth and at six-months postbirth. Weight was assessed on scales calibrated monthly. Length was measured supine, using a roller meter with infant feet at zero position and bringing the headboard down to the crown of the head. Standardized z-scores (height-for-age, weight-for-age, height-for-weight-for age) were generated using new World Health Organization (WHO) child growth standards for infants under 24 months of age and calculated from WHO Anthro-2005 software. Infants were then categorized as underweight if they had a weight-for-age $\mathrm{z}$-score (WAZ) of $<-2$ and stunted if they had a length-for-age $\mathrm{z}$-score (HAZ) of $<-2$ [41]. Newborn infants were also provided with a "Road to Health" card on which birth weight, length at birth and delivery date were recorded. These measures were highly consistent with the interviewers' measure $(r>0.9)$ and, therefore, we only examine the results using the interviewer collected data.

\section{Data analysis}

Before analyzing infant outcomes, we checked for confounding variables and found no significant differences in baseline demographic characteristics within or across study conditions among the full sample or among mothers depressed antenatally. Using SAS
PROC MIXED (version $9^{\circ} 2$; SAS Institute Inc., Cary, North Carolina, USA), we modelled infant growth zscores longitudinally using an unstructured time trend in hierarchical linear regressions that included two random effects: one to model the correlation of repeated measures within a participant and another to model the correlation between participants clustered within the same neighborhood. Explanatory variables included indicators for intervention (PIP; 1 = intervention, $0=\mathrm{SC}$ ) and antenatal depression (DEP; $1=$ depressed, $0=$ not depressed), time (TIME; $0=$ birth, $1=$ post-birth, 2 = six months), and the two- and three-way interactions of PIP, DEP, and TIME. Intervention as a moderator of the depression effect on the change in $\mathrm{z}$ score over time (PIP*DEP*TIME) was the effect of interest, and we considered a 2 -sided p-value $<0.05$ to be significant. Using SAS PROC GLIMMIX, we also modelled the moderating effect of intervention on infant growth $(\mathrm{z}$-score $\geq-2)$ cross-sectionally at each assessment period using logistic random effects regressions controlling for neighbourhood clustering. Explanatory variables included indicators for intervention (PIP; 1 = intervention, $0=\mathrm{SC}$ ), antenatal depression (DEP; 1 = depressed, 0 = not depressed, and their interaction. Intervention's moderation of depression's impact on infant growth (PIP*DEP) was the effect of interest, and we set the criteria for a 2 -sided $\mathrm{p}$-value $<0.05$ to be significant.

\section{Results}

\section{Sample characteristics}

Table 1 summarises the self-reports of mothers in the PIP and SC conditions at the baseline interview conducted at mean of 26 weeks gestational age $(\mathrm{SD}=$ 8.2 weeks). There were no differences in gestational age at recruitment across conditions. Women were similar across conditions on: alcohol use in pregnancy (26\%), rates of prior LBW infants (16\%), depression (35\%) and social support measures. They were also highly similar on criteria used in cluster matching such as type of housing (31\% formal), source of water (53\% on site), presence of flush toilet on premises (55\%), and presence of electricity on premises (90\%); and also on demographic characteristics of age, marital status, education, employment status and household income. One significant baseline difference between PIP and SC was noted: among women who had been pregnant before, mothers in the SC had a higher mean number of previous births.

Figure 1 outlines the flow of participants throughout the study. Sample retention rates at follow-up were high, collected within narrow time frames, and similar across intervention conditions: $88 \%$ of participants were assessed at six months $\left(\mathrm{M}=6^{\circ} 8\right.$ months, $\left.\mathrm{SD}=0^{\circ} 8\right)$. There were no significant selection effects between 
Table 1 Baseline characteristics

\begin{tabular}{|c|c|c|c|c|c|c|c|}
\hline \multirow[b]{2}{*}{ Demographic characteristics } & \multicolumn{2}{|c|}{ intervention $(N=644)$} & \multicolumn{2}{|c|}{$\mathrm{SC}(N=594)$} & \multicolumn{2}{|c|}{ Total $(N=1238)$} & \multirow[t]{2}{*}{ P-Value } \\
\hline & $n$ & $(\%)$ & $n$ & (\%) & $n$ & (\%) & \\
\hline Mean age (SD) & 26.5 & $(5.5)$ & 26.3 & (5.6) & 26.4 & (5.5) & 0.783 \\
\hline Mean highest education level (SD) & 10.3 & $(1.8)$ & 10.3 & $(1.8)$ & 10.3 & (1.8) & 0.639 \\
\hline Married or lives with partner & 377 & $(58.5)$ & 324 & $(54.6)$ & 701 & $(56.6)$ & 0.524 \\
\hline Sexual partner, past 3 months & 580 & $(90.1)$ & 522 & $(87.9)$ & 1102 & $(89.0)$ & 0.284 \\
\hline Ever employed & 129 & $(20.0)$ & 104 & $(17.5)$ & 233 & $(18.8)$ & 0.341 \\
\hline Monthly household income >2000 Rand & 280 & $(45.6)$ & 279 & $(48.1)$ & 559 & $(46.8)$ & 0.484 \\
\hline Formal housing & 197 & $(30.6)$ & 191 & $(32.2)$ & 388 & (31.3) & 0.958 \\
\hline Water on site & 333 & $(51.7)$ & 327 & $(55.1)$ & 660 & $(53.3)$ & 0.983 \\
\hline Flush toilet & 340 & $(52.8)$ & 343 & $(57.7)$ & 683 & $(55.2)$ & 0.923 \\
\hline Electricity & 569 & $(88.4)$ & 543 & $(91.4)$ & 1112 & $(89.8)$ & 0.843 \\
\hline \multicolumn{8}{|l|}{ Maternal Health } \\
\hline Non-primipara & 422 & $(65.5)$ & 394 & $(66.3)$ & 816 & (65.9) & 0.714 \\
\hline Mean number of live births (SD) & 1.5 & $(0.9)$ & 1.7 & $(1.1)$ & 1.6 & $(1.0)$ & 0.005 \\
\hline Previous LBW infants & 61 & $(14.5)$ & 69 & $(17.5)$ & 130 & $(15.9)$ & 0.117 \\
\hline Tested for TB, lifetime & 206 & $(32.0)$ & 210 & $(35.4)$ & 416 & (33.6) & 0.225 \\
\hline Test positive TB, lifetime & 53 & $(8.2)$ & 50 & $(9.4)$ & 103 & (8.8) & 0.438 \\
\hline \multicolumn{8}{|l|}{ Mental Health } \\
\hline EPDS $>13$ & 238 & $(37.0)$ & 195 & $(32.8)$ & 433 & $(35.0)$ & 0.265 \\
\hline \multicolumn{8}{|l|}{ HIV } \\
\hline Ever tested for HIV & 590 & $(91.6)$ & 550 & $(92.6)$ & 1140 & $(92.1)$ & 0.566 \\
\hline Women living with HIV & 149 & $(25.5)$ & 146 & $(26.7)$ & 295 & $(26.1)$ & 0.649 \\
\hline \multicolumn{8}{|l|}{ Alcohol } \\
\hline Drank any alcohol, month prior to pregnancy discovery & 155 & $(24.1)$ & 129 & $(25.8)$ & 284 & $(24.8)$ & 0.592 \\
\hline AUDIT-C $>2$, month prior to pregnancy discovery & 113 & $(17.6)$ & 101 & $(20.2)$ & 214 & $(18.7)$ & 0.323 \\
\hline Drank any alcohol after pregnancy discovery & 56 & $(8.7)$ & 49 & $(9.8)$ & 105 & $(9.2)$ & 0.540 \\
\hline AUDIT-C > 2, after pregnancy discovery & 41 & $(6.4)$ & 24 & $(4.8)$ & 65 & (5.7) & 0.385 \\
\hline Drank any alcohol, anytime during pregnancy & 172 & $(26.7)$ & 154 & $(25.9)$ & 326 & (26.3) & 0.808 \\
\hline
\end{tabular}

${ }^{*}$ P-values from linear (continuous variables) or logistic (binary) random effects regressions, adjusted for neighbourhood clustering

mothers who were successfully reassessed over the six months post-birth and those who were not, and there were no serious adverse events or unintended effects of the study implementation.

As we have reported elsewhere, the intervention did not have an impact on reducing maternal depression at 6 months post-natally [42]. About one in four mothers (30\%) reported depression with a score on the EPDS over 13 and $16.5 \%$ had an EPDS score greater than 18 .

As shown in Fig. 2, the intervention has a significant positive impact on depression's effect on the change in HAZ between birth and 6 months (estimated mean difference of $0.699 ; 95 \% \mathrm{CI}=[0.051,1.346] ; p=0.034)$. The infants of depressed pregnant women in the PIP group were similar in height to the children of non-depressed mothers in both the PIP and the SC conditions at birth, but significantly taller (HAZ) at 6 months than the infants of pregnant depressed mothers in the SC condition.

WAZ scores were not significantly different between the conditions (PIP vs SC) or depression status at 6 months. Children in each condition and, regardless of maternal depression had WAZ scores above $0(\mathrm{Z}=$ mean of children globally in WAZ).

There was a significant difference for intervention condition by antenatal status on the change in WFHZ scores between post-birth and 6 months (estimated mean difference of $-1.022 ; 95 \% \mathrm{CI}=[-1.762,-0.282]$; $p=0.007)$. Children of depressed PIP mothers were at the WHO recommended WFHZ at 6 months (i.e., WFHZ $=0$ ); however, the children of the non-depressed mothers in the SC and PIP and children of depressed $\mathrm{SC}$ were significantly above the WHO recommended WFHZ at 6 months. 


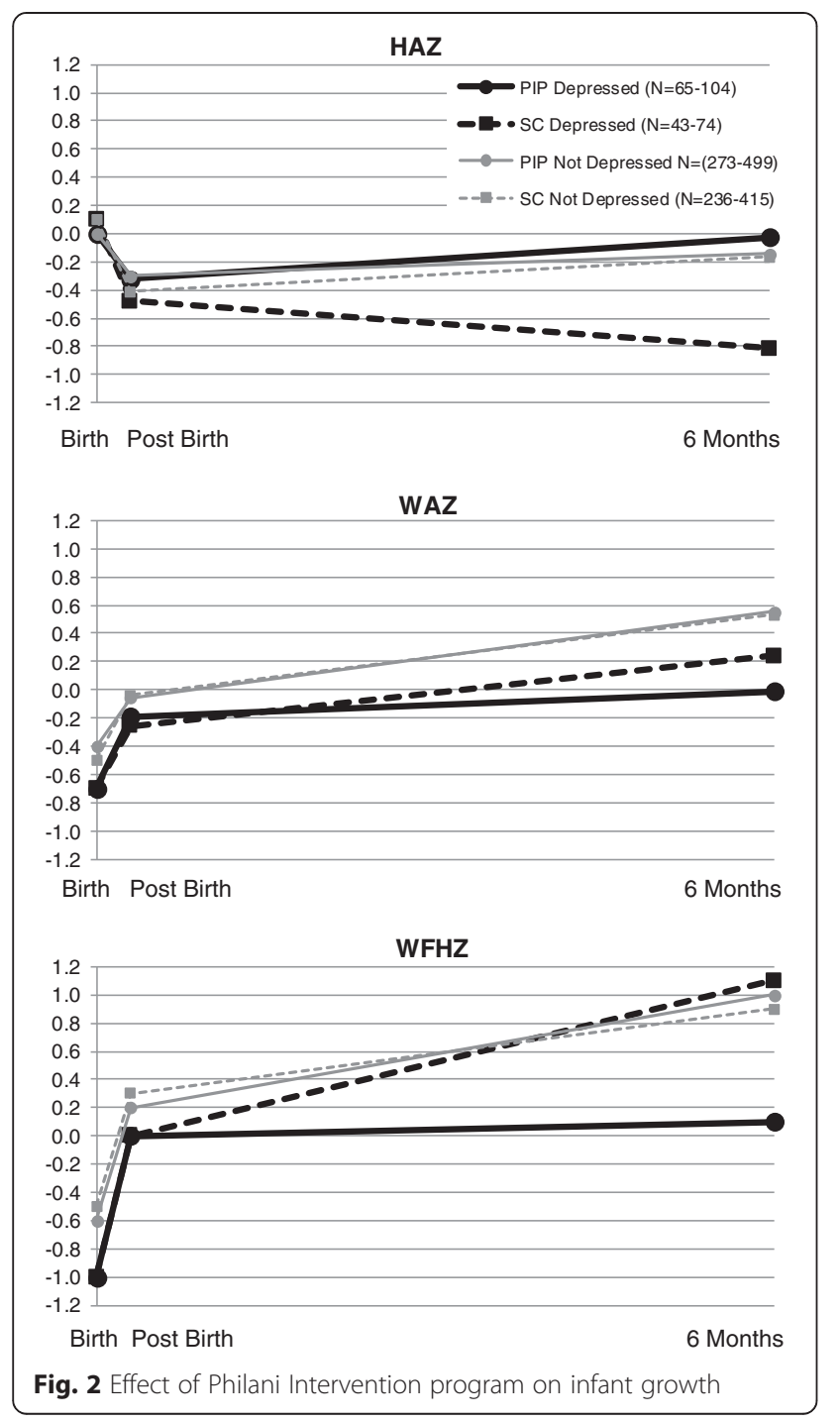

As shown in Table 2, the intervention did not significantly moderate antenatal depression's effect on infant growth at 6 months. At two weeks post-birth, there was a trend toward the intervention moderating maternal depression's harmful effect on infant HAZ $\mathrm{z} \geq-2$, with percentage of infants with HAZ $\mathrm{z} \geq-2$ higher for depressed mothers compared to non-depressed mothers in the PIP condition ( $10.8 \%$ vs. $6.7 \%$, respectively), but lower for depressed vs. non-depressed mothers in the SC group (15.2 \% vs. $12.1 \%$, respectively; $p=0.075)$.

\section{Discussion}

The children of antenatally depressed mothers in the intervention condition were more often in the normative range for length for their age over time compared to children of depressed mothers in the control condition. Children of antenatally depressed children in the control condition tended to be significantly shorter at birth. Because only $16.5 \%$ were significantly depressed (EPDS < 18), the power to detect significant differences in growth is substantially reduced. The rate of stunting (being two SD lower in height) was more than double at two weeks post birth $(\mathrm{OR}=2.36)$ and similar 6 months later $(\mathrm{OR}=$ 1.8) compared to children of depressed mothers in the intervention condition. However, with clustering of neighbourhoods and the reduced sample size, the confidence intervals are too large to have precision in evaluating if this is a significant difference. These rates suggest that CHW may be able to reduce stunting of depressed mothers by focusing on encouraging depressed mothers to maintain caretaking. Our findings contribute to a growing body of literature examining the impact of community based interventions on child health in the context of perinatal depression $[32,43]$.

Table 2 Intervention's moderation of depression's (EPDS > 18) effect on infant growth results at each assessment

\begin{tabular}{|c|c|c|c|c|c|c|c|c|c|c|c|}
\hline & \multicolumn{4}{|c|}{$\mathrm{PIP}(N=644)$} & & & & & \multirow{3}{*}{ Depressed-not, PIP vs. SC } & \multirow{3}{*}{$\begin{array}{l}\text { OR, PIP vs. SC } \\
\text { moderation of } \\
\text { depression }(95 \% \mathrm{Cl})^{*}\end{array}$} & \multirow{3}{*}{$P$-Value* } \\
\hline & \multicolumn{2}{|c|}{$\begin{array}{l}\text { EPDS } \leq 18 \\
(n=535)\end{array}$} & \multicolumn{2}{|c|}{$\begin{array}{l}\text { EPDS > 18 } \\
(n=109)\end{array}$} & \multicolumn{2}{|c|}{$\begin{array}{l}\text { EPDS } \leq 18 \\
(n=499)\end{array}$} & \multicolumn{2}{|c|}{$\begin{array}{l}\text { EPDS }>18 \\
(n=95)\end{array}$} & & & \\
\hline & $n$ & $\%^{\mathrm{A}}$ & $n$ & $\%^{\mathrm{B}}$ & $n$ & $\%^{\mathrm{C}}$ & $n$ & $\%^{\mathrm{D}}$ & & & \\
\hline \multicolumn{12}{|c|}{ Weight-for-age-z-score $\geq-2$} \\
\hline 2 weeks & 465 & 93.2 & 96 & 92.3 & 367 & 93.1 & 65 & 90.3 & $1.90 \%$ & $1.33(0.51,3.42)$ & 0.559 \\
\hline 6 months & 447 & 97.8 & 94 & 97.9 & 405 & 98.1 & 70 & 94.6 & $3.60 \%$ & $3.37(0.54,21.24)$ & 0.195 \\
\hline \multicolumn{12}{|c|}{ Height-for-age-z-score $\geq-2$} \\
\hline 2 weeks & 438 & 89.2 & 97 & 93.3 & 342 & 87.9 & 60 & 84.5 & $7.50 \%$ & $2.34(0.92,5.94)$ & 0.075 \\
\hline 6 months & 410 & 91.1 & 86 & 89.6 & 357 & 87.1 & 57 & 77 & $8.60 \%$ & $1.81(0.76,4.31)$ & 0.179 \\
\hline \multicolumn{12}{|c|}{ Weight-for-height-z-score $\geq-2$} \\
\hline 2 weeks & 424 & 88.9 & 91 & 90.1 & 340 & 90.7 & 58 & 87.9 & $4.00 \%$ & $1.55(0.56,4.26)$ & 0.4 \\
\hline 6 months & 438 & 96.5 & 88 & 91.7 & 399 & 97.3 & 71 & 95.9 & $-3.40 \%$ & $0.62(0.14,2.76)$ & 0.562 \\
\hline
\end{tabular}


The intervention's negative effect on WFHZ score is a reflection of the positive intervention effect on height (HAZ). Intervention children are taller and significantly less likely to be stunted, their weight for height is at the desirable mean score of 0 (normative weight) at 6 months post birth. Children of antenatally depressed mothers in the control condition were shorter, but of similar weight compared to the children of antenatally depressed mothers in the intervention condition and children of non-depressed mothers in both conditions. Therefore, when calculating WFHZ, the children are relatively heavier at their height, above the desirable mean of 0 and similar to the children of non-depressed mothers in both conditions.

The PIP intervention's benefit in height was achieved in the context of a study where CHW were not specifically trained to address depression (through screening or treatment) and in which the prevalence of depressive symptoms were highly similar in the intervention and control conditions over time. A study by Rahman and colleagues [32] examined whether or not delivering a cognitive behavioural therapeutic intervention to depressed mothers using village $\mathrm{CHW}$ women would improve infant growth [32], and found that directly addressing depression had a large impact on reducing maternal depression, but had no impact on improving infant growth. The work of Tripathy and colleagues in Nepal, on the other hand [43] found significant reductions in neonatal mortality amongst moderately depressed women in a group- based intervention programme aimed at improving social support and problem solving [43]. Similar to findings of our South African study, this result was achieved without specifically targeting perinatal depression. It is likely that the psycho-educational activities of the PIP intervention providing skills to address alcohol, nutrition, and HIV enabled women to be better caretakers of their infants, in spite of being depressed.

Increasingly, antenatal depression is being seen as an important public health concern. The link between postnatal depression and compromised child development is well established [20,44], but this is less the case with antenatal depression although this relationships is increasingly a target of investigation. Our data suggest that interventions during the antenatal period are crucial. Our findings provide support for training CHW as generalists, in order to address the highest priority health issues in a local community. Training of CHW to address caretaking, problem solving and support, appears to benefit child growth [41]. Treating depression does not necessarily remove the conditions that frequently cause or exacerbate depression - such as poverty and interpersonal violence. On the other hand, providing mothers the tools to help their infants thrive (something most mothers are highly motivated about) allows them to act toward a powerfully motivated goal. Indeed, an inability to help their child thrive may be a real driver of maternal depression. While our findings also provide evidence that there are benefits for child development in the context of perinatal depression, the primary preventive nature of community -based interventions, such as PIP, may not ameliorate moderate to severe depression.

Intervening in multiple health risks concurrently, even by paraprofessional $\mathrm{CHW}$, appears to benefit child growth, even when mothers are depressed during pregnancy and remain depressed. The mechanism by which the caretaking influences height and stunting, but not weight gain is a mystery. It is surprising that the children of PIP mothers who were antenatally depressed had children who were less stunted but did not weigh as much as the children in the SC condition who had depressed mothers. In other analyses we have conducted [40], PIP mothers were significantly more likely to breastfeed their infants and to breastfeed longer. The children of antenatally depressed PIP mothers also breastfed their children longer. Breastfeeding often results in lower weights, which may explain that the intervention children were of normal weight per height.

More research is needed in order to establish the optimal mix of interventions that are sufficiently targeted (screening for perinatal depression and providing referral or treatment), while also being sufficiently generalised and horizontally integrated given the resources constraints of LMIC. Given the explanatory models of mental illness in many countries [11, 45] which link disturbance to social adversity and social problems rather than individualistic explanations, interventions targeted at these social determinants of health may be more acceptable to local communities. Given what is known about the causes of depression, it also may be more appropriate. As a clinical condition, depression is often highly stigmatized as an individual deficiency. In some contexts, interventions may be more efficacious when framed as addressing community challenges, rather than as a treatment program for individuals $[11,45]$. The PIP model did not target individual depression, but aimed to improve parenting and child health. Every household was visited in the neighbourhood, regardless of such risks as HIV and alcohol use. The strategic approach adopted in the PIP program is similar to the "Thinking Healthy" programme of Rahman and colleagues [32] and uses cognitive behavioural change principles as a generic method of intervention for a broad range of social problems, rather than depression alone.

The relationship between maternal mental health and child growth is complex [12]. It is possible that interventions focussed on maternal depression may not fully address this complexity [46], while generalist models of implementation are not sufficiently targeted to make a 
significant impact on moderate to severe perinatal maternal depression. Evidence is needed on what the optimal implementation models are. The improvements we have seen in this study warrant continued tracking to examine sustainability and durability of an intervention's impact when delivered by CHW.

Finally, Philani is a NGO which has survived 30 years. Over that time, it has developed core relationships with staff in the Department of Health, community leaders, church officials, clinics and a broad range of key community roles. Unlike many other NGOs, it has welldeveloped accountability and training systems for both CHW and supervisors. Diffusion of this model to other NGO without these strengths is likely to face many obstacles. The strengths of this study are that it is a cluster randomized controlled trial of mothers monitored during pregnancy and the similarity of the mothers and infants and the high retention in the intervention and the control condition are additional evidence of the strengths of this design. We did not conduct full diagnostic interviews for depression, which is a limitation of our current design.

\section{Conclusion}

We showed benefits to infant growth in the context of antenatal depression when community health workers intervened to address concurrent community health risks, but not specifically trained to address depression through screening or treatment. This adds to a growing body of evidence identifying sustainable and effective strategies to improve maternal and child outcomes in LMIC.

\section{Competing interests}

The authors declare that they have no competing interests

\section{Authors' contributions}

MJR, IML, and MT conceived of the study, planned the study design, and led preparation of the manuscript. JMH conducted the data analyses and authored sections of the manuscript. MJO and CMW consulted on study design, measure selection, data analyses, and edited and commented on the manuscript. MJR had full access to all the data in the study and takes responsibility for the integrity of the data and the accuracy of the data analysis. All authors read and approved the final manuscript

\section{Acknowledgements \\ This study was funded by NIAAA Grant \# 1R01AA017104 and supported by $\mathrm{NIH}$ grants MH58107, 5P30AI028697, and UL1TR000124. MT is supported by the National Research Foundation (South Africa), and is a lead researcher in the Centre of Excellence in Human Development (University of the Witwatesrand). No authors have any conflicts of interest: no support from any organization for the submitted work, no financial relationships with any organizations that might have an interest in the submitted work in the previous three years, and no other relationships or activities that could appear to have influenced the submitted work. The funder had no role in study design, data collection and analysis, interpretation of data, decision to publish, or preparation of the manuscript.}

\section{Funding}

National Institute of Alcohol Abuse and Alcoholism, 1RO1AA017104-01A1; National Institutes of Health grants MH58107, 5P30AI028697, and UL1TR000124; llifa Labantwana Foundation, South Africa.

\section{Author details}

${ }^{1}$ Department of Psychology, Stellenbosch University, Private Bag X1, Matieland, South Africa. ${ }^{2}$ Department of Psychiatry and Biobehavioral Sciences, University of California, Los Angeles, USA. ${ }^{3}$ Philani Maternal, Child Health, and Nutrition Project, Cape Town, South Africa. ${ }^{4}$ Department of Anthropology, Emory University, Atlanta, USA

Received: 29 May 2014 Accepted: 10 September 2015

Published online: 23 September 2015

\section{References}

1. Vos T, Flaxman AD, Naghavi M, Lozano R, Michaud C, et al. Years lived with disability (YLDs) for 1160 sequelae of 289 diseases and injuries 1990-2010: a systematic analysis for the Global Burden of Disease Study 2010. Lancet. 2012;380:2163-96.

2. Whiteford HA, Degenhardt L, Rehm J, Baxter AJ, Ferrari AJ, et al. Global burden of disease attributable to mental and substance use disorders: findings from the Global Burden of Disease Study 2010. Lancet. 2013;382:1575-86.

3. Kessler RC. Epidemiology of women and depression. J Affect Disord. 2003;74:5-13.

4. WHO. Mental Health Atlas 2011. Geneva: World Health Organization; 2011.

5. Patel V, Kleinman A. Poverty and common mental disorders in developing countries. Bulletin World Health Organization. 2003;81:609-15.

6. Tomlinson M, O'Connor MJ, le Roux IM, Stewart J, Mbewu N, et al. Multiple risk factors duringpregnancy in South Africa: the need for a horizontal approach to perinatal care. Prev Sci. 2014;15:277-82.

7. Tomlinson M, Cooper P, Murray L. The mother-infant relationship and infant attachment in a south African peri-urban settlement. Child Dev. 2005;76:1044-54

8. Hanlon C. Maternal depression in low- and middle-income countries. International Health. 2013:5:4-5.

9. Grantham-McGregor S, Cheung YB, Cueto S, Glewwe P, Richter L, et al. Developmental potential in the first 5 years for children in developing countries. Lancet. 2007:369:60-70.

10. Murray L, Cooper PJ. Intergenerational transmission of affective and cognitive processes associated with depression: infancy and the pre-school years. In: Goodyer IM, editor. Unipolar Depression: A Lifespan Perspective. Oxford: Oxford University Pres; 2003. p. 17-46.

11. Hanlon C, Whitley R, Wondimagegn D, Alem A, Prince M. Postnatal mental distress in relation to the sociocultural practices of childbirth: an exploratory qualitative study from Ethiopia. Soc Sci Med. 2009;69:1211-9.

12. Stewart RC. Maternal depression and infant growth: a review of recent evidence. Matern Child Nutr. 2007;3:94-107.

13. Orr S, James S, Blackmore Prince C. Maternal prenatal depressive symptoms and spontaneous preterm births among African-American women in Baltimore, Maryland. Am J Epidemiol. 2002;56:797-802.

14. Diego M, Field T, Hernandez-Reif M, Schanberg S, Kuhn C, et al. Prenatal depression restricts fetal growth. Early Hum Dev. 2008;85:65-70.

15. Field H, Healy B, Goldstein S, Perry S, Bendell D, et al. Infants of depressed mothers show "depressed" behavior even with nondepressed adults. Child Dev. 1988:59:1569-79.

16. Pawlby S, Hay D, Sharp D, Waters C, O'Keane V. Antenatal depression predicts depression in adolescent offspring: prospective longitudinal community-based study. J Affect Disord. 2009;113:236-43.

17. World Health Organisation. Mental health aspects of women's reproductive health: A global review of literature. Geneva, Switerzland: WHO; 2009.

18. Rahman A, lqbal Z, Bunn J, Lovel H, Harrington R. Impact of maternal depression on infant nutritional status and illness: a cohort study. Arch Gen Psychiatry. 2004;61:946-52.

19. Rahman A, Harrington R, Bunn J. Can maternal depression increase infant risk of illness and growth impairment in developing countries? Child: Care, Health \& Development. 2002;28:51-6.

20. Rochat TJ, Tomlinson M, Barnighausen T, Newell ML, Stein A. The prevalence and clinical presentation of antenatal depression in rural South Africa. Journal of Affective Disorders. 2011;135:362-73.

21. Rochat TJ, Tomlinson M, Barnighausen T, Newell ML, Stein A. The prevalence and clinical presentation of antenatal depression in rural South Africa. J Affect Disord. 2011;135:362-73.

22. Cooper PJ, Tomlinson M, Swartz L, Woolgar M, Murray L, et al. Post-partum depression and the mother-infant relationship in a South African peri-urban settlement. Br J Psychiatry. 1999;175:554-8. 
23. Hartley M, Tomlinson M, Greco E, Comulada WS, Stewart J, et al. Depressed mood in pregnancy: prevalence and correlates in two Cape Town peri-urban settlements. Reprod Health. 2011;8:9.

24. Walker SP, Wachs TD, Grantham-McGregor S, Black MM, Nelson CA, et al. Inequality in early childhood: risk and protective factors for early child development. Lancet. 2011:378:1325-38.

25. Rahman A. Maternal depression and child health: the need for holistic health policies in developing countries. Harvard Health Policy Rev. 2005;6:70-80.

26. Rahman A, Bunn J, Lovel H, Creed F. Maternal depression increases infant risk of diarrhoeal illness: --a cohort study. Arch Dis Child. 2007:92:24-8.

27. Harpham T, Huttly S, De Silva MJ, Abramsky T. Maternal mental health and child nutritional status in four developing countries. J Epidemiol Community Health. 2005;59:1060-4.

28. Tomlinson M, Cooper PJ, Stein A, Swartz L, Molteno C. Post-partum depression and infant growth in a South African peri-urban settlement. Child: Care, Health \& Development. 2006;32:81-6.

29. Stewart RC, Umar E, Kauye F, Bunn J, Vokhiwa M, et al. Maternal common mental disorder and infant growth-a cross-sectional study from Malawi. Matern Child Nutr. 2008:4:209-19.

30. Bryce J, Daelmans B, Dwivedi A, Fauveau V, Lawn JE, et al. Countdown to 2015 for maternal, newborn, and child survival: the 2008 report on tracking coverage of interventions. Lancet. 2008;371:1247-58.

31. Poobalan AS, Aucott LS, Ross L, Smith WC, Helms PJ, et al. Effects of treating postnatal depression on mother-infant interaction and child development: systematic review. Br J Psychiatry. 2007;191:378-86.

32. Rahman A, Malik A, Sikander S, Roberts C, Creed F. Cognitive behaviour therapy-based intervention by community health workers for mothers with depression and their infants in rural Pakistan: a cluster-randomised controlled trial. Lancet. 2008;372:902-9.

33. Aboud FE, Singla DR. Challenges to changing health behaviours in developing countries: a critical overview. Soc Sci Med. 2012.

34. Rotheram-Borus MJ, le Roux IM, Tomlinson M, Mbewu N, Comulada WS, et al. Philani plus (+): a mentor mother community health worker home visiting program to improve maternal and infants' outcomes. Prev Sci. 2011;12:372-88.

35. Groenewald P, Bradshaw D, Daniels J, Zinyakatira N, Matzopoulos R, et al. Local-level mortality surveillance in resource-limited settings: a case study of Cape Town highlights disparities in health. Bull World Health Organ. 2010;88:444-51.

36. World Health Organization. Co-trimaxazole prophylaxis for HIV-exposed and HIV-infected infants and children: practical approaches to implementation and scale up. Geneva: World Health Organization; 2009.

37. Tomlinson M, Solomon W, Singh Y, Doherty T, Chopra M, et al. The use of mobile phones as a data collection tool: a report from a household survey in South Africa. BMC Med Inform Decis Mak. 2009;9:51.

38. Cox JL, Holden JM, Sagovsky R. Detection of postnatal depression. Development of the 10-item Edinburgh Postnatal Depression Scale. Br J Psychiatry. 1987;150:782-6.

39. First MB, Spitzer RL, Gibbon M, Williams JB. Structured clinical interview for DSM-IV axis 1. Neew York: New York State Psychiatric Institute; 1996.

40. Rochat T, Tomlinson M, Newell ML, Stein A. Depression among pregnant women testing for HIV in rural South Africa, Implications for VTC and PMTCT. Gabarone, Botswana: 9th International AIDS Impact Conference; 2009.

41. Mei Z, Grummer-Strawn LM. Standard deviation of anthropometric Z-scores as a data quality assessment tool using the 2006 WHO growth standards: a cross country analysis. Bull World Health Organ. 2007;85:441-8.

42. le Roux IM, Tomlinson M, Harwood JM, O'Connor MJ, Worthman CM, et al. Outcomes of home visits for pregnant mothers and their infants: a cluster randomized controlled trial. AIDS. 2013;27:1461-71.

43. Tripathy $P$, Nair N, Barnett S, Mahapatra R, Borghi J, et al. Effect of a participatory intervention with women's groups on birth outcomes and maternal depression in Jharkhand and Orissa, India: a cluster-randomised controlled trial. Lancet. 2010;375:1182-92.

44. Murray L, Arteche A, Fearon P, Halligan S, Goodyer I, et al. Maternal postnatal depression and the development of depression in offspring up to 16 years of age. J Am Acad Child Adolesc Psychiatry. 2011;50:460-70.

45. Hanlon C, Medhin G, Alem A, Araya M, Abdulahi A, et al. Sociocultural practices in Ethiopia: association with onset and persistence of postnatal common mental disorders. Br J Psychiatry. 2010;197:468-75.

46. Hanlon C. Maternal depression in low-and middle-income countries. International Health. 2013;5:4-5.

\section{Submit your next manuscript to BioMed Central and take full advantage of:}

- Convenient online submission

- Thorough peer review

- No space constraints or color figure charges

- Immediate publication on acceptance

- Inclusion in PubMed, CAS, Scopus and Google Scholar

- Research which is freely available for redistribution

Submit your manuscript at www.biomedcentral.com/submit 